\title{
BMJ Open Oncology patients' experiences in experimental medicine cancer trials: a qualitative study
}

\author{
Chelsea Sawyer (D) , , Laurie Preston, ${ }^{1}$ Sally Taylor, ${ }^{1,2}$ Michelle Davies, ${ }^{3}$ \\ Louise Carter, ${ }^{3,4}$ Matthew Krebs,, ${ }^{3,4}$ Natalie Cook, ${ }^{3,4}$ Donna Graham,, \\ Fiona Thistlethwaite, ${ }^{3,4}$ Janelle Yorke ${ }^{1,2}$
}

To cite: Sawyer C, Preston L, Taylor S, et al. Oncology patients' experiences in experimental medicine cancer trials: a qualitative study. BMJ Open

2021;11:e047813. doi:10.1136/ bmjopen-2020-047813

- Prepublication history and additional supplemental material for this paper are available online. To view these files, please visit the journal online (http://dx.doi.org/10.1136/ bmjopen-2020-047813).

Received 11 December 2020 Accepted 25 August 2021

Check for updates

(C) Author(s) (or their employer(s)) 2022. Re-use permitted under CC BY-NC. No commercial re-use. See rights and permissions. Published by BMJ.

${ }^{1}$ Christie Patient Centred Research, The Christie NHS Foundation Trust, Manchester, UK

${ }^{2}$ Division of Nursing, Midwifery and Social Work; School of Health Sciences, The University of Manchester, Manchester, UK

${ }^{3}$ The Experimental Cancer Medicine Team, The Christie NHS Foundation Trust,

Manchester, UK

${ }^{4}$ Division of Cancer Sciences, The University of Manchester, Manchester, UK

Correspondence to

Dr Chelsea Sawyer;

chelsea.sawyer@nhs.net

\section{ABSTRACT}

Objectives The study aimed to explore patients' experiences of experimental cancer medicine (ECM) clinical trials.

Design The study's design was qualitative. Two focus groups with patients were undertaken followed by semistructured interviews, to explore patients' experiences of ECM clinical trials. Interviews and focus groups were audiorecorded and transcribed verbatim. Data were analysed using thematic analysis.

Setting A regional cancer centre (tertiary care) in NorthWest England.

Participants Twelve patients (aged 52-79) participated in one of the two focus groups and 22 patients (aged 42-83) participated in interviews.

Primary outcome measure Patients' experiences of an ECM trial.

Results Four main themes were identified from the analysis: decision making, information needs, the experience of trial participation and impact of trial participation. Subthemes are presented in the manuscript. Conclusion To make fully informed decisions about trial participation, patients required the simplification of trial information and wanted more information about side effects, their response to trial treatment and the overall trial progress throughout the trial. Patients highlighted the need for improvement for the support provided to their family and friends.

\section{INTRODUCTION}

Experimental cancer trials (or early phase clinical trials) play an important role in progressing and advancing cancer treatments. It is estimated in the UK one in five patients with cancer participate in clinical trials. ${ }^{1}$ Early phase clinical trials (phase I and non-randomised phase II) are designed to assess the safety of novel drugs, pharmacodynamics and pharmacokinetics. ${ }^{2}$ Drug doses are gradually increased in phase I trials, to explore safety and optimum dose. In phase II trials, drug efficacy, side effects and safety are also investigated. Early phase clinical research primarily focuses on physical outcomes, including appropriate drug

\section{Strengths and limitations of this study}

- The study explored the perspectives of a diverse group of patients approached to participate in early phase clinical trials, allowing the study to capture an abundance of experiences. Aspects of diversity included age range, duration on trial, disease group and phase of the trial. Patients who had been ineligible or withdrawn from the trial were also included.

- The study generated comprehensive and detailed insights as interviews were conducted to build on experiences highlighted in focus groups, and interviews were conducted until data saturation.

- A limitation is the cross-sectional nature of the study, experiences and perspectives may change throughout the trial process.

- Participants were recruited from one comprehensive cancer centre, patients' experiences may vary across hospitals.

dosing, treatment toxicities, survival and response rate. ${ }^{2}$ Limited attention is afforded to patient experience, consequently, little is understood about the personal impact of trial participation. ${ }^{3}$

Understanding patient experience is particularly important in early phase trials, where significant adverse events associated with treatment toxicity may outweigh possible therapeutic benefit. ${ }^{4}$ Undesirable side effects are an important factor in shaping patients' experiences of trial involvement, influencing their psychological well-being, sense of hope and potentially increasing fear of death. ${ }^{5}$ Furthermore, patients may not fully understand the burden and demands of participation in clinical trials, and the impact trial participation could have on their and their loved one's quality of life (QoL). ${ }^{3}$

Despite the various physical, emotional and practical challenges, patients generally report positive experiences of trial participation and feel an increased sense of 'control' over their illness. ${ }^{5}$ Moore suggested trial participation 
reflects a coping strategy against hopelessness. ${ }^{6}$ When standard treatment is ineffective, clinical trials are perceived by some to offer a 'second chance' at finding a cure. ${ }^{3}$ Early phase trials can be perceived by others to be a 'last-ditch effort' for patients who are otherwise considered to have exhausted all other treatment options. ${ }^{4}$ Cox also found participants derived comfort from being closely monitored by clinicians due to the belief they were in 'expert' hands, and in providing a sense of purpose through helping others. ${ }^{3}$ However, patients often misunderstand trial information, their understanding and the meanings patients ascribe to their participation will determine how they make sense of their experiences throughout the trial process. ${ }^{7}$

Patient experience is considered to be an integral component of excellent healthcare. ${ }^{8}$ As outlined in the National Health Service (NHS) Outcomes Framework, a deeper understanding of patient perceptions of trial involvement will drive quality improvement and aid learning. ${ }^{8}$ Yet there is limited understanding of patients' experiences of participating in early phase clinical trials. Due to the aims of early phase trials and the uncertainties around drug side effects and safety, this study aimed to explore the experiences of participants in experimental cancer medicine (ECM) clinical trials.

\section{METHOD}

\section{Study design}

In this qualitative study, focus groups and semistructured interviews were used. Focus groups were conducted first to explore patients' experiences of ECM trials allowing patients to discuss similarities and differences in their experiences. The main themes/experiences from the focus groups were explored in more depth in semistructured interviews. ${ }^{9}$ The same topic guide was used for focus groups and interviews (online supplemental appendix 1). Questions captured patients' experiences of trial introduction and participation and their decisionmaking process regarding participating in the trial they were offered. For those on observational trial studies, the interviews focused on their experiences of trial introduction and decision-making process.

\section{Sample/data collection}

Participants were recruited from a regional cancer centre in North-west England. The inclusion criteria for the study were (A) any cancer type and (B) anyone who has been screened for an observational or phase I-II ECM trial. Participants were excluded if they were unable to provide informed consent, or comprehend written English.

After identification by the clinical team, potential participants were approached by the research team, who explained the study and provided written information. Participants were given the opportunity to ask questions about study participation or the information provided. Written informed signed consent was obtained. Twenty-one face-to-face interviews were conducted in a

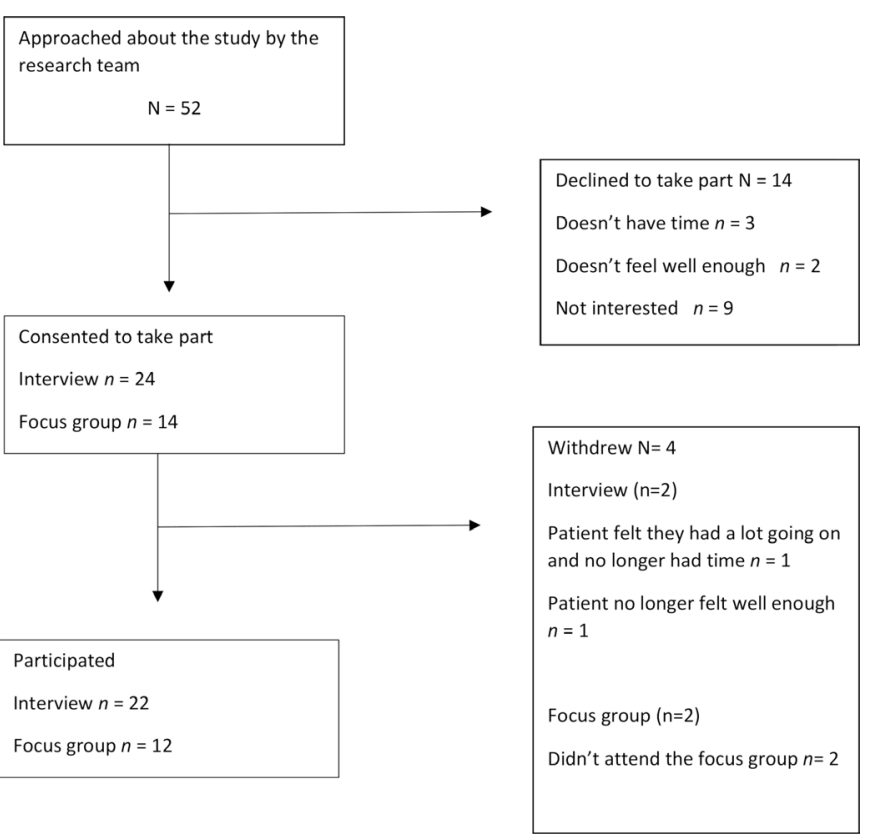

Figure 1 Study flow diagram.

quiet hospital room and one face-to-face interview was conducted at the patient's home, determined by the patient's preference.

Both focus groups were conducted face-to-face in a quiet hospital room. The interviews and focus groups were audiorecorded and lasted from 14 to $62 \mathrm{~min}$ and 48 to $108 \mathrm{~min}$, respectively.

Figure 1 presents the study's recruitment process. Participant demographics are presented in table 1.

\section{Data analysis}

Interviews and focus groups were analysed by hand using an inductive thematic approach. ${ }^{10}$ The six-phase guidelines of Braun and Clarke were used. ${ }^{10}$ After familiarisation with the data, two authors (JY and CS) coded an initial transcript and produced a coding document. After creating the coding document, themes were developed and discussed. Any disagreements regarding codes and themes were discussed between the authors until a consensus was agreed. The codes and themes were then refined to improve clarity. Two reviewers then coded an additional three transcripts and compared these to determine inter-rater reliability $(86 \%)$. One researcher (CS) subsequently coded the remaining transcripts. Themes and interpretations of the data were discussed in regular meetings (JY and CS).

\section{Patient and public involvement}

The patient representative is a patient with secondary breast cancer, who has participated in an early phase clinical trial. They reviewed study documents (participant information sheets, informed consent form, interview schedule) and provided feedback. After analysis, the main themes were discussed with the study team and patient representative, who all provided feedback. A summary of 
Table 1 Participants' demographic information

\begin{tabular}{|c|c|c|}
\hline & $\begin{array}{l}\text { Interviews } \\
(n=22)\end{array}$ & $\begin{array}{l}\text { Focus groups } \\
(n=12)\end{array}$ \\
\hline Age range (years (median)) & $42-83(65.5)$ & $52-79(68.5)$ \\
\hline Gender (female \%) & 59 & 8 \\
\hline \multicolumn{3}{|l|}{ Ethnicity \% } \\
\hline White British & 95 & 100 \\
\hline Chinese & 5 & \\
\hline \multicolumn{3}{|l|}{ Marital status (\%) } \\
\hline Single & 4.55 & 16.67 \\
\hline Married/domestic partner & 90.90 & 66.67 \\
\hline Widowed & 4.55 & 8.33 \\
\hline Divorced & - & 8.33 \\
\hline \multicolumn{3}{|l|}{ Employment status (\%) } \\
\hline Self-employed & - & 8.33 \\
\hline Retired & 75.00 & 83.34 \\
\hline Unable to work & 18.75 & 8.33 \\
\hline Homemaker & 6.25 & - \\
\hline \multicolumn{3}{|l|}{ Performance status (\%) } \\
\hline 0 & 52.94 & 45.45 \\
\hline 1 & 47.06 & 54.55 \\
\hline \multicolumn{3}{|l|}{ Type of trial n (\%) } \\
\hline $\begin{array}{l}\text { Patients who are considered } \\
\text { for the trial and then deemed } \\
\text { ineligible (are often referred to } \\
\text { as 'screen fail') }\end{array}$ & $2(9)$ & - \\
\hline Observational & $2(9)$ & - \\
\hline Phase I & $9(41)$ & $7(67)$ \\
\hline Phase II & $9(41)$ & $5(33)$ \\
\hline Time on trial (<1 year, \%) & 54.55 & 50 \\
\hline \multicolumn{3}{|l|}{ Disease group } \\
\hline Breast & 31.82 & - \\
\hline Colorectal & 13.64 & 16.67 \\
\hline Head and neck & - & 8.33 \\
\hline Haematological & 9.09 & - \\
\hline Lung & 22.72 & 16.67 \\
\hline Leukaemia & & 8.33 \\
\hline Lymphoma & 18.18 & 41.67 \\
\hline Penile & 4.55 & - \\
\hline Renal & - & 8.33 \\
\hline
\end{tabular}

study results will be sent to all participants who requested it.

\section{Reflexivity}

Interviews were conducted sensitively by five researchers (JY, CS, RL, SB and DC) who were not part of the patients' clinical team and all have experience in interviewing people with cancer or regarding sensitive topics (selfharm). The data analysis was primarily conducted by one researcher (CS) who took an inductive approach and was unfamiliar with the relevant literature at that time. They had no previous experience working in clinical trials, or any personal experiences with clinical trials. This allowed the researcher to analyse the data without looking for preconceived themes or experiences. The analysis was then discussed with the research team (JY, CS, LC and $\mathrm{MD})$, to minimise any biases which may have occurred. All members of the research team have relevant research or clinical experience. Researchers conducted balanced interviews and focus groups, and reminded patients the research team was not involved in the clinical trial.

\section{RESULTS}

We identified four main themes: decision making, information needs, experience of trial participation, impact of trial participation. The subthemes are described below with supporting quotations provided in table 2 . All themes were mentioned in both the interviews and focus groups. However, false hope was more prominent in the interviews. All patients mentioned fear around disclosing side effects, patients in the focus group emphasised the impact of not disclosing side effects and discussed how to try and encourage patients to disclose side effects.

\section{Decision making \\ Decision-makers}

Patient preference regarding involvement in decision making varied. Some patients highlighted the importance of including family and friends in their decisions, whereas others felt it was only their decision to make. Due to difficulties understanding the information, uncertainties around trials, and patients' perception of doctor's expertise, some patients relied on the doctors to make the best decision for them.

No other option

A few patients perceived clinical trials as their only option and for those who were ineligible for the trial, this view led to feelings of despair and uncertainty about their options. Conversely, the majority of patients felt clinical trials provided them with another treatment option. This was particularly important for patients who did not want the alternative treatment options.

Hope

Clinical trials provided the majority of patients with hope. For some it was a potential chance for a cure, stopping the progression of their cancer, and/or extending their life. While others hoped their participation would help others with cancer in the future.

\section{Information needs}

Wealth/volume and simplicity of information

Patients wanted enough information about their choices to make the best decision regarding treatment. Patients highlighted the need for more simplified trial information, as the information they received was scientific and sometimes difficult to understand. 
Table 2 Presents the themes and their subthemes with supporting quotations

\section{Decision making}

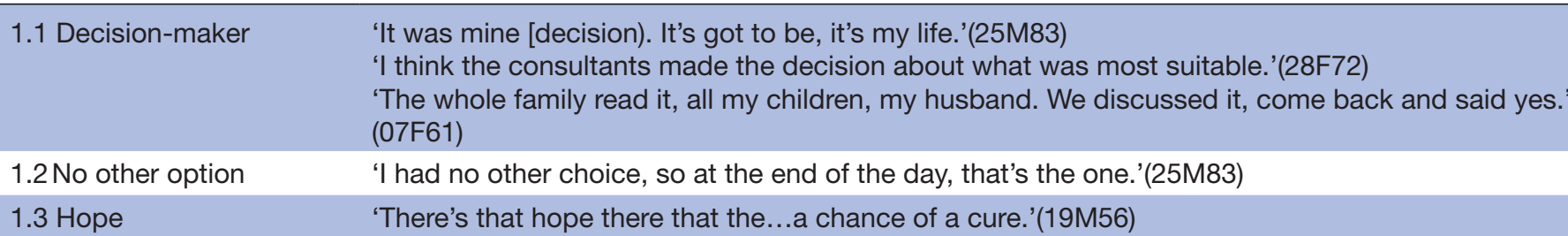

1.3 Hope 'There's that hope there that the...a chance of a cure.'(19M56)

\section{Information needs}

2.1 Vol and simplicity of 'doctors know all the technical terms, but we don't, most of us; and it has to be said in plain information English'(22F52)

2.2 Side effects

'I don't remember anybody saying, before you go on this, your thyroid could do this, and it will be permanent'(23F68)

'Well I think the list of possible side effects is they just think of everything they can think of that might go wrong and list them all down' (FG2)

2.3 Updates throughout 'I want him to say to me, now look here, if this doesn't work it's chemo.'(21F70) treatment

2.4 Provision of false hope 'if they hadn't built my expectation, then the crash wouldn't have been as hard' (03M42)

2.5 Support available 'you do feel that there's a void like, you know, where do I get that information [about support).'(FG2)

3. Experience of trial

3.1 Patient centred 'the clinical trials team were I felt tailoring their treatment of me.'(24F56)

'it didn't feel personal; it felt as though I was being treated as a number that was insignificant.'(22F52)

3.2 Disclosing side effects 'is the most frightening thing, at that point in time when you come off that point when you've been given, this is your one hope to live and somebody says, I'm just going to take it away from you, and that's the end of the matter.' (FG2)

'and I made the mistake of telling them about some of the side effects' (FG2)

'if you don't tell them [side effects), then you're compromising not only the trial but you're compromising yourself more importantly.'(FG2)

'if they [trial team] said to you that if you were to disclose the side-effects you're having, that they would be more likely to change your treatment levels or do something about it, other than say on or off because it's the fear of the on or off is the most frightening thing'.(FG2)

\section{Impact of trial participation}

4.1 Quality of life 'It's an impact on your life having to come in every two weeks, especially the thing I was on initially was an all-day effort' (FG2)

'I was in and out like a yo yo And I didn't realise it was the trial'(14M66)

'Our life has changed absolutely beyond recognition. I had a good job and we were very active, cycled everywhere and went diving on holiday and all of those things which we can't do now'(24F56)

4.2 Time 'the frequency of the visits is good and bad, as I say It's travelling every week but having that line of contact and support weekly is great.' (24F56)

4.3. Family

'It's a really valid question to ask around carers and family members and how are they coping'(26F48)

'it's difficult for my daughter because she had her studies and she came with me every time'(29M55)

$\begin{array}{ll}\text { 4.4 Financial } & \text { 'It costs you a lot of money'(07F61) } \\ \text { 4.5 Psychological impact } & \text { 'Depressed. it got me down, the waiting'(28F72) } \\ & \text { 'So I'm on the waiting list. They may pick somebody else. I don't know.' (25M83) }\end{array}$

Quotes from the interviews are presented as participant's ID, gender ( $M=$ male, F=female) and age (in years). Quotes from the focus groups are presented as FG and number (1 or 2).

Side effects

Patients were divided on whether they had received enough information about possible side effects of the trial before participation, with some patients reporting they were not fully informed. Patients recognised it might be difficult to provide this information, as the purpose 
of clinical trials is to identify side effects. One patient felt the risk of permanent side effects had not been fully explained, and prior knowledge of this risk would have affected their decision to participate.

\section{Updates throughout treatment}

During the trial, patients wanted updated information regarding (1) their response to treatment, (2) alternative treatment options, (3) the success of the overall trial to date and (4) the experiences of other patients on the trial. This information helped them to re-evaluate their trial involvement and make decisions about future participation.

\section{Provision of false hope}

A few patients felt they received false hope and were misled about potential personal benefit from trial participation. These patients believed this false hope reduced their ability to cope with a negative response to treatment. These patients felt information about possible outcomes of the trial should highlight the risks and the possibility the trial may not work, rather than focusing on potential benefits.

Patients who were ineligible for the trial (screen fail) recalled how upsetting it was to be told they were ineligible. One patient even stated it felt like a 'death sentence'.

\section{Support available}

Patients were informed of whom to contact if they required medical support. However, many were unaware of the psychological support available and could not recall doctors discussing psychological support options. Some patients who were aware of psychological support, highlighted difficulties accessing the support due to the length of treatments and distance travelling to the hospital. The majority of patients did not know if there was any psychological/financial/practical support available for family members.

\section{Experience of trial participation \\ Patient centred}

Many patients perceived themselves as a guinea pig concerning side effects and some felt their treatment was impersonal. The majority of patients, however, reported receiving personalised care and some discussed the flexibility to fit appointments around their priorities.

\section{Disclosing side effects}

Patients, especially those who saw the trial as their only treatment option, were concerned about disclosing side effects in case it impacted trial participation. Some patients who disclosed side effects even reported 'downplaying' side effects and/or regretting disclosing side effects due to withdrawal from the trial.

This theme was discussed in great detail in the second focus group, with one patient who was taken off the trial admitting they would be reluctant to disclose side effects in future trials. Other patients discussed the internal conflict between the fear of withdrawal from the trial and the risk to themselves if they did not disclose side effects. Some patients were aware by not disclosing side effects they are compromising the trial and the patient's safety.

Patients in the focus group felt they needed more information from the clinical team about what would happen if they experienced side effects. Particularly emphasising that experiencing side effects does not always result in withdrawal from the trial, instead, the dosage may be reduced.

\section{Impact of trial participation}

\section{Quality of life}

Trial participation affected many aspects of a participant's life including QoL, free time, finances and their family. Patients highlighted the need to fit their life around the trial schedule (due to the frequency and long duration of trial days, and travelling to the hospital). Patients frequently stated once the trial had finished they could get their 'life back'.

The impact on QoL was mixed. Some patients believed their QoL had improved, for example, they were able to perform activities they had been unable to due to ill health. In contrast, other patients were unable to partake in regular activities or trips away, due to side effects or frequent hospital visits, which on occasion required inpatient admission.

\section{Time}

Patients discussed the burden of clinical trials on their time, due to the frequency and duration of hospital visits. Some patients reported requiring the next day to recover and rest, perceiving they had 'lost' another day due to the trial. However, some benefits to frequent hospital visits were reported including seeing experienced doctors and additional monitoring, care and support they perceived they would not receive with standard treatment. Patients reported a lot of waiting around, which was tiring but understandable. Some patients were frustrated when they were not informed of delays to their treatment.

An unanticipated impact of the trial was on holidays and trips away. Trial schedules often prevented patients from going away for their preferred duration. Travel insurance was also often difficult to obtain. There were concerns around what would happen if the patient became ill on holiday and if the treatment they received from other hospitals could react with trial treatment or affect trial participation. Limitation to travel was especially difficult for patients who were unable to see their family who lived abroad.

\section{Family}

Patients felt their participation in a clinical trial was a shared experience with their families and discussed the psychological impact of trial participation on their family and friends. Some patients felt their spouses were 'trapped' or they were a 'burden' to their family. While others mentioned their family/friends had to change 
their usual activities due to their participation in the trial. Patients highlighted the need for support for their family/friends. Many patients felt it was crucial that clinical trial teams ask family/friends about the impact of the trials on them as well.

\section{Financial}

Some patients described the financial burden of participating in trials, due to travel costs, as well as food and drinks needed during visits. These patients were not aware of any financial aids available.

\section{Psychological impact}

Patients mentioned experiencing anxiety and depression, during the screening process, due to uncertainties around their trial eligibility. Patients feared 'their' trial space could be allocated to another while awaiting their results, due to their knowledge of limited trial spaces. One patient even felt 'rushed' to make a decision.

\section{DISCUSSION}

Overall, the majority of patients had a positive experience and received patient-centred care. To aid decision making regarding initial and continued participation, patients identified several areas of improvement (1) simplification of trial information (2) more information on side effects, (3) regular updates on response to treatment and (4) information about alternative options. Patients needed more information about support available for themselves and their family members. Patients admitted to being reluctant to inform clinical trial teams about side effects experienced.

Patients found trial information too scientific and difficult to understand, which is consistent with previous studies. ${ }^{711} 12$ Patients wanted more information about the risk of side effects but mentioned the long list of side effects could be daunting. However, patients often focused on the anticipated personal benefit they would get from the trial rather than potential side effects. Previous studies reported patients often have unrealistic expectations about their potential benefit and reduced susceptibility to side effects when compared with other patients. ${ }^{6}$ 13-17 To improve comprehension of information, ensure patients provide fully informed consent, and understand the potential risks. Donovan recommends interviewing patients while reviewing study documentation to identify any aspects that are unclear or could be misinterpreted. ${ }^{18}$

Misinterpretation of trial information could have led to 'false hope' (the patient hopes the treatment results in a cure, improvement of health or prolongation of life). ${ }^{19}$ For example, patients overestimating personal benefit (therapeutic misconceptions) or if the clinical team emphasised the benefits of being on trials (regular appointments, great care, extra attention to their health and potential benefit for future patients). ${ }^{13} 1719$ False hope was perceived to reduce the patient's ability to cope with bad news, and lead to feelings of frustration and disappointment being amplified and more destructive. ${ }^{19}$ This calls into question whether the patient gave fully informed consent. Early phase dose-escalation trials may not lead to personal medical benefit to patients of the trial, yet this is often a reason for participation. ${ }^{15}$ The unlikelihood of personal benefit needs to be emphasised more clearly to the patients. ${ }^{141520-25}$ From the current evidence, it seems the hope to obtain medical benefit is not indicative of compromised informed consent. ${ }^{1521} 22$ However, when introducing patients to trials and providing them with possible treatment options there is a need for equipoise (the assumption there is not one 'better' treatment option). ${ }^{18} 2627$ Any inkling of preferential treatment combined with the patient's belief that doctors and nurses act in the patient's best interest, could lead to patients feeling they have been given false hope. ${ }^{318}$

A few patients reported feeling rushed to make a decision; these patients had anxieties that if they did not decide quickly they may lose the trial to another patient. It is crucial patients are given the time and information they require, to make a fully informed decision about trial participation. The patient's anxieties may be due to their therapeutic misconceptions or unrealistic expectations about the benefit, combined with their knowledge of small recruitment numbers across multiple sites. ${ }^{13} 22$ Clinical trial teams should consider these factors when discussing trial participation. In addition, the wording used to inform patients they are 'eligible' could affect patient's decision making regarding trial participation. Patients frequently report feeling 'lucky' or 'honoured' they were eligible for the trial, as it gave them another chance for a cure. ${ }^{26} 28$ Therefore, it was important to capture patients' experiences who were ineligible for clinical trials. ${ }^{34}$ Those who were ineligible felt disappointed and were out of treatment options. Brown et $a 2^{26}$ found patients suggested the phrase "the trial is suitable for you" could be used instead of 'eligible', as the phrase was perceived to objectify the study and highlight the possibility of other treatment options. In addition the use of 'unsuitable' may minimise the disappointment felt by those ineligible for the study. ${ }^{26}$

To aid decision making regarding continued participation in early phase clinical trials, patients desired regular updates about their response to trial treatment. Patients desired information about other patients' experiences of side effects while on the trial and response to the trial and more detailed feedback about the trial progress (ie, recruitment and retention). This is in line with previous studies, which also found patients frequently shared information with each other about side effects and their experience on the trial. ${ }^{2429} 30$ Providing information about other patients' experiences will depend on the information received from the trial sponsor. However, it is crucial information is presented in a way that does not lead to false hope emphasising, there are no guaranteed benefits or side effects, and patients have different reactions to treatment. 
The main aim of the majority of early phase trials is to investigate the safe dosage range and side effects experienced by patients. ${ }^{3}$ Therefore, to ensure patients' safety and validity of the trial, it is crucial patients are honest about side effects and their severity. ${ }^{13}$ Yet many patients admitted holding back information about side effects due to fear of being taken off the trial.

The disclosure of side effects is likely influenced by patients' beliefs. ${ }^{13}{ }^{28}$ Previous studies found trial patients believed higher doses were more effective and side effects were caused by effective treatment. ${ }^{31} 32$ To reduce fear and address any misconceptions (regarding dose level and effectiveness, and withdrawal of trial if they disclose side effects), these misconceptions could be incorporated into a question prompt list (a list comprised of standard questions to prompt discussion between patient and doctor) highlighting dose reduction as an option if side effects are disclosed. ${ }^{1433}$ However, further research is required to see if providing this information would reduce the underreporting of side effects.

Another possible option to improve the accuracy of reporting side effects is the integration of electronic patient-reported outcomes (ePROs) in clinical trials. Patients often delay reporting side effects leading to their effect being minimised. ${ }^{16} 33$ The integration of ePROs enables regular monitoring of patients' side effects and can improve the accuracy and timing of reporting side effects. ${ }^{35}$ EPROs aid real-time data collection, which can be used to notify their clinical trial team of adverse events, allowing for earlier clinical decisions, and provide relevant medical advice, tailored to patients' responses. ${ }^{37}$ Therefore, enhancing the patients' quality of care and communication with their clinical team. ${ }^{35}$

Participation in clinical trials led to a reduced QoL for some patients and not all were aware their poor health was due to treatment toxicity and attributed it to their cancer instead. Some of these patients may have a limited life expectancy and their quality of time left may be more important than staying on the trial. ${ }^{3}$ Therefore, clinical trial teams should have ongoing discussions throughout the trial about the patient's trial response, risks and benefits of trial continuation, and other treatment options including palliative care. These discussions will enable patients to make fully informed choices and find a balance between trial participation and QoL. ${ }^{3} 38$

As well as impacting patient's QoL, patients can experience undesirable side effects, which can have a negative impact on patient's psychological well-being. ${ }^{5}$ Yet the majority of patients felt they did not need emotional/ psychological support. Despite this perception, patients experienced psychological distress (anxiety and/ or depression) at various points throughout the trial (initial screening to determine if patients were eligible or awaiting test results). Patients, who are physically or psychologically impacted, may benefit from specialist palliative care ${ }^{39}$ However, due to the conflicting beliefs (palliative care is for end of life whereas the trial provides hope for another treatment option) patients were less likely to access specialist palliative care. ${ }^{39}$ The clinical trial teams may need to provide more information and education about the supports available to patients and the potential benefit of specialist palliative care alongside trial treatment. ${ }^{39}$

Trial participation can require both the patient and their families' time, physical and emotional energy, and some parts of their lives to be put on hold. ${ }^{40}$ Therefore, patients felt it was important their family had psychological, financial and/or practical support. Family/friends acting in a caregiver role (including managing medications, appointment schedules, finances and/or providing emotional support and/or physical care) commonly experience burden and depression. ${ }^{41}$ Patients with advanced cancer also perceived their caregivers' lives were on hold when the caregiver was their child. ${ }^{41}$ Additionally, caregivers of trial patients experience greater distress and anxiety when compared with the population norms of caregivers of cancer patients. ${ }^{42}$ Untreated anxiety and depression can lead to poor physical and mental health, as well as reduced QoL for carers and potentially patients as well. ${ }^{41}$ Despite this, very few patients knew if there was any support available to their family and friends, other than the medical support provided by the clinical trials team. The clinical trial team should provide information about various support services available to patients and their families throughout the trial. However, there is minimal literature on the most effective support for carers of cancer patients and further research is required to identify the support needs of carers. ${ }^{41} 42$

\section{Limitations}

One limitation is the cross-sectional nature of the study, as experiences and perspectives may vary throughout the trial. Future studies should use a longitudinal design targeting people at various stages throughout the trial. A second limitation is the study's sample. All participants are from a single comprehensive cancer centre, patients' experiences may vary across hospitals and clinical trial units. However, the study has a large sample size and heterogeneous population in terms of cancer diagnosis, duration of trial participation, and stage of the clinical trial (only two patients interviewed were 'screen fails', but it was still important to capture their experiences). The ethnic diversity of the sample was limited and therefore not representative of the area where the data was collected. However, recruitment levels for clinical trials are lower for ethnic minority groups. The majority of trial patients are white British, therefore, the sample used was representative of people who usually participate in clinical trials. ${ }^{43}$

\section{CONCLUSION}

Patients require the simplification of trial information and want more information regarding side effects, available support, their response to trial treatment and overall trial progress throughout the trial, to make fully informed 
decisions about ongoing trial participation. Due to the trial burden, ongoing discussions are required to help patients find the balance between QoL and trial participation. Patients were unaware of the support available for their family and wanted more support for their family.

Correction notice This article has been corrected since it first published. Author name 'Fiona Thistlethwaite' has been updated.

Twitter Michelle Davies @michmdavies and Natalie Cook @oncocook

Acknowledgements Patients, Carer's, the Christie Experimental Cancer Medicine Team. We would also like to thank Elaine Blowers, Rana Lee, Grant Punnett, and Sarah Bellhouse for their help with the study. We would also like to thank J.T for all their help with the study.

Contributors JY and ST developed the study design. JY has supervised the study. CS and JY analysed the materials. CS and LP wrote the manuscript. JY, ST, LC, NC, MK, DG, FT and MD gave substantial input throughout the development and writing of the paper. JT (patient representative) was involved with the study design and discussion of main themes.

Funding The study was funded by Manchester Experimental Cancer Medicine Centres (ECMC) and The Christie CRF Charity, the grant number for this award is A01008. The study was supported by the NIHR Manchester Biomedical Research Centre.

Competing interests None declared.

Patient consent for publication Not applicable.

Ethics approval Ethical approval was gained from the appropriate Research Ethics Committee (reference number 18/SC/0299) and the local NHS Trust.

Provenance and peer review Not commissioned; externally peer reviewed.

Data availability statement No data are available. The interview transcripts are available to show proof of the paper. However, they would only be available for legal purposes. They are confidential and can only be given access to in case of legal Requirements

Supplemental material This content has been supplied by the author(s). It has not been vetted by BMJ Publishing Group Limited (BMJ) and may not have been peer-reviewed. Any opinions or recommendations discussed are solely those of the author(s) and are not endorsed by BMJ. BMJ disclaims all liability and responsibility arising from any reliance placed on the content. Where the content includes any translated material, BMJ does not warrant the accuracy and reliability of the translations (including but not limited to local regulations, clinical guidelines, terminology, drug names and drug dosages), and is not responsible for any error and/or omissions arising from translation and adaptation or otherwise.

Open access This is an open access article distributed in accordance with the Creative Commons Attribution Non Commercial (CC BY-NC 4.0) license, which permits others to distribute, remix, adapt, build upon this work non-commercially, and license their derivative works on different terms, provided the original work is properly cited, appropriate credit is given, any changes made indicated, and the use is non-commercial. See: http://creativecommons.org/licenses/by-nc/4.0/.

ORCID iD

Chelsea Sawyer http://orcid.org/0000-0003-2596-1580

\section{REFERENCES}

1 Brown H G. Every patient a research patient? Evaluating the current state of research in the NHS, 2015. Available: https:// www.cancerresearchuk.org/sites/default/files/cruk_every_patient_ may2015_web.pdf [Accessed 22 Apr 2020].

2 Friedman LM, Furberg CD, DeMets DL. Introduction to clinical trials. In: Fundamentals of clinical trials. Springer, 2015: 1-23.

3 Cox K. Researching research: Patients' experiences of participation in phase I and II anti-cancer drug trials. European Journal of Oncology Nursing 1999;3:143-52.

4 Mahipal A, Nguyen D. Risks and benefits of phase 1 clinical trial participation. Cancer Control 2014;21:193-9.

5 Wootten AC, Abbott JM, Siddons HM, et al. A qualitative assessment of the experience of participating in a cancer-related clinical trial. Support Care Cancer 2011;19:49-55.
6 Moore S. A need to try everything: patient participation in phase I trials. J Adv Nurs 2001;33:738-47.

7 Harrop E, Noble S, Edwards M, et al. "I didn't really understand it, I just thought it'd help": exploring the motivations, understandings and experiences of patients with advanced lung cancer participating in a non-placebo clinical IMP trial. Trials 2016;17:1-12.

8 Department of Health. NHS outcomes framework 2016-17, 2016. Available: https://www.gov.uk/government/uploads/system/uploads/ attachment data/file/513157/NHSOF at a glance.pdf

9 Lambert SD, Loiselle CG. Combining individual interviews and focus groups to enhance data richness. J Adv Nurs 2008;62:228-37.

10 Braun V, Clarke V. Using thematic analysis in psychology. Qual Res Psychol 2006;3:77-101.

11 Beardsley E, Jefford M, Mileshkin L. Longer consent forms for clinical trials compromise patient understanding: so why are they lengthening? J Clin Oncol 2007;25:e13-14.

12 Stunkel L, Benson M, McLellan L, et al. Comprehension and informed consent: assessing the effect of a short consent form. IRB 2010;32:1.

13 McManus L, Fisher JA. To report or not to report: exploring healthy volunteers' rationales for disclosing adverse events in phase I drug trials. AJOB Empir Bioeth 2018;9:82-90.

14 Appelbaum PS, Roth LH, Lidz CW, et al. False hopes and best data: consent to research and the therapeutic misconception. Hastings Cent Rep 1987;17:20-4.

15 Jansen LA, Appelbaum PS, Klein WMP, et al. Unrealistic optimism in early-phase oncology trials. IRB 2011;33:1.

16 Jansen LA, Mahadevan D, Appelbaum PS, et al. Perceptions of control and unrealistic optimism in early-phase cancer trials. $J$ Med Ethics 2018;44:121-7.

17 Pentz RD, White M, Harvey RD, et al. Therapeutic misconception, misestimation, and optimism in participants enrolled in phase 1 trials. Cancer 2012;118:4571-8.

18 Donovan JL, Rooshenas L, Jepson M, et al. Optimising recruitment and informed consent in randomised controlled trials: the development and implementation of the quintet recruitment intervention (QRI). Trials 2016;17:1-11.

19 Musschenga B. Is there a problem with false hope? US: Oxford University Press, 2019: 44. 423-41.

20 Agrawal M, Emanuel EJ. Ethics of phase 1 oncology studies: reexamining the arguments and data. JAMA 2003;290:1075-82.

21 Miller FG, Joffe S. Benefit in phase 1 oncology trials: therapeutic misconception or reasonable treatment option? Clin Trials 2008;5:617-23.

22 Agrawal M, Grady C, Fairclough DL, et al. Patients' decision-making process regarding participation in phase I oncology research. J Clin Oncol 2006;24:4479-84.

23 Godskesen T, Nygren P, Nordin K, et al. Phase 1 clinical trials in endstage cancer: patient understanding of trial premises and motives for participation. Support Care Cancer 2013;21:3137-42.

24 Locock L, Smith L. Personal experiences of taking part in clinical trials-a qualitative study. Patient Educ Couns 2011;84:303-9.

25 Nurgat ZA, Craig W, Campbell NC, et al. Patient motivations surrounding participation in phase I and phase II clinical trials of cancer chemotherapy. Br J Cancer 2005;92:1001-5.

26 Brown RF, Butow PN, Butt DG, et al. Developing ethical strategies to assist oncologists in seeking informed consent to cancer clinical trials. Soc Sci Med 2004;58:379-90.

27 Brown RF, Butow PN, Ellis P, et al. Seeking informed consent to cancer clinical trials: describing current practice. Soc Sci Med 2004;58:2445-57.

28 Brédart A, Bodson S, Le Tourneau C, et al. Patients' perceived tolerance of side effects in phase I cancer clinical trials: A qualitative study. Eur J Cancer Care 2017;26:e12596.

29 Cox K, Moghaddam N, Bird L, et al. Feedback of trial results to participants: a survey of clinicians' and patients' attitudes and experiences. Eur J Oncol Nurs 2011;15:124-9.

30 McManus L, Davis A, Forcier RL, et al. Appraising harm in phase I trials: healthy volunteers' accounts of adverse events. J Law Med Ethics 2019;47:323-33.

31 Jenkins V, Solis-Trapala I, Langridge C, et al. What oncologists believe they said and what patients believe they heard: an analysis of phase I trial discussions. J Clin Oncol 2011;29:61-8.

32 Miller FG, Joffe S. Phase 1 oncology trials and informed consent. $J$ Med Ethics 2013;39:761-4.

33 Brown RF, Butow PN, Boyle F, et al. Seeking informed consent to cancer clinical trials; evaluating the efficacy of doctor communication skills training. Psychooncology 2007;16:507-16.

34 Coolbrandt A, Van den Heede K, Vanhove E, et al. Immediate versus delayed self-reporting of symptoms and side effects during chemotherapy: does timing matter? Eur J Oncol Nurs 2011;15:130-6. 
35 Bennett AV, Jensen RE, Basch E. Electronic patient-reported outcome systems in oncology clinical practice. CA Cancer J Clin 2012;62:336-47.

36 Holch P, Warrington L, Bamforth LCA, et al. Development of an integrated electronic platform for patient self-report and management of adverse events during cancer treatment. Ann Oncol 2017;28:2305-11.

37 Pietanza MC, Basch EM, Lash A, et al. Harnessing technology to improve clinical trials: study of real-time informatics to collect data, toxicities, image response assessments, and patient-reported outcomes in a phase II clinical trial. J Clin Oncol 2013;31:2004-9.

38 Bangs R, Crispino T. From the other side: the patient perspective on cancer clinical trials. Urol Oncol 2019;37:331-5.

39 Bellhouse S, Galvin L, Turner L, et al. Phase I cancer trials: a qualitative study of specialist palliative care. BMJ Support Palliat Care 2020;10:234-41.
40 Goode KT, Haley WE, Roth DL, et al. Predicting longitudinal changes in caregiver physical and mental health: a stress process model. Health Psychol 1998;17:190-8.

41 Shilling V, Starkings R, Jenkins V, et al. The pervasive nature of uncertainty-a qualitative study of patients with advanced cancer and their informal caregivers. J Cancer Surviv 2017;11:590-603.

42 Kessler ER, Moss A, Eckhardt SG, et al. Distress among caregivers of phase I trial participants: a cross-sectional study. Support Care Cancer 2014;22:3331-40.

43 Symonds RP, Lord K, Mitchell AJ, et al. Recruitment of ethnic minorities into cancer clinical trials: experience from the front lines. Br J Cancer 2012;107:1017-21.

44 Godden S, Ambler G, Pollock AM. Recruitment of minority ethnic groups into clinical cancer research trials to assess adherence to the principles of the Department of health research governance framework: national sources of data and general issues arising from a study in one hospital trust in England. $J$ Med Ethics 2010;36:358-62. 